\title{
The CARS Model and Binary Opposition Structure
}

\author{
Tomoko Sawaki
}

\begin{abstract}
This paper proposes solutions for a number of difficulties that Swalean generic structure analysis has been experiencing concerning the identification methods it applies to generic structure components. It does this by integrating the Greimassian method, a structuralist method of reducing elements to the minimal units of signification. In making this proposal, it points out that the underlying goal of Swalean genre analysis, which aims to classify various academic elements that differ in their degree of prototypicality into an umbrella of family resemblance, can be considered analogous to the structuralist goal of reducing elements to the minimal units despite the different theoretical groundings of these two approaches. It demonstrates the compatibility of these approaches by reducing some of the components of the Creating A Research Space (CARS) model; namely, it reduces Move 1 and Move 2 into one unit. Additional emerging elements that are similarly complex in academic writing, such as postmodern personal anecdotes, can also be sorted out into this unit. It concludes that methods in semiotics may offer useful frameworks for the applied disciplines where signification processes need to be revealed in analysis.
\end{abstract}

Keywords: genre analysis, generic structure analysis, Greimassian Semiotic Square, academic discourse, the CARS model

\section{Introduction}

The purpose of this paper is to present the potential of an integrative approach for genre analysis that will combine the Greimassian structuralist approach and the Swalean approach, by using the CARS model, which is the mainstream generic-structure analytical framework for the introductory portions of research articles in academic discourse analysis (Swales, 1990, 2004). The Swalean approach may appear fundamentally different from the Greimassian one in that it does not take the idea of an underlying essential structure into consideration. However, prototype theory (Rosch, 1975) and the concept of family resemblance (Wittgenstein, 1958), which Swalean genre analysis draws on for its rationale (Swales, 1990), have much in common with the Greimassian claim of the existence of an underlying structure, as this study shows. I demonstrate this by showing how some problems with the Swalean approach can be successfully resolved by integrating the Greimassian method of reducing elements to the minimal unit of meaning (semes/the paired actantial functions) (Greimas, 1983 [1966]).

Since their first appearance in 1981, the Swalean generic structure models have been applied widely to studies of academic writing in the field of English for Specific Purposes (ESP); in particular, the Creating A Research Space (CARS) model has often been used for the generic structure analysis of the basic structure of the introductory portions of typical research articles written in English. The CARS model does a good job of analyzing generic structure in these articles; at the same time, however, a number of studies reported limitations in doing analysis using the Swalean model (Cope and Kalantzis, 1993; Chu, 1996; Bloor, 1998; Lewin, Fine and Young, 2001; Lorés, 2004). One of the limitations they claimed is a lack of applicability of the model to atypical instances of the genre, which causes endless descriptions of generic structure components which don't fit the predefined categories (Cope and Kalantzis, 1993). Another limitation reported (Lewin et al., 2001, Lorés, 2004) is the model's confusing identification method for generic components in that it combines cognitive and lexicogrammatical/semantic criteria. That is, to establish his generic structure analysis identification criteria, Swales drew on prototype theory (Rosch, 1975) and the concept of family resemblance (Wittgenstein, 1958). However, as pointed out by Lewin et al, (2001) lexicogrammatical cues such as negation in the determiner are at the same time considered to serve as a criterion (Lewin et al., 2001), as shown in Section 2.

Formalistic approaches tend to be distanced from the mainstream social approaches in the fields where social factors are emphasized due to the conception that formalism highlights form at the expense of ignoring social factors. Two other traditions of genre 
studies in ESP (cf. Hyon, 1996), new rhetoric studies and systemic functional linguistics (SFL), emphasize social factors. SFL takes the semiotic perspective toward language (Halliday, 1985. However, their bi-planer view is not extended to the generic structure level. Hence, their generic structure models (cf. Hasan, 1989; Martin and Rose, 2008) do not consider relations between generic structure components as part of the signification process. As Paltridge (1995) pointed out, however, neither SFL nor Swales' approaches to genre analysis have "provided, within a single integrated framework, a model for genre analysis which incorporates both social and cognitive aspects of language comprehension and production" (Paltridge, 1995, pp. 393-394).

As the anthropology of Lévi-Strauss demonstrated, the deductive method in the structuralist tradition in fact achieves its clear descriptions of sociocultural factors by separating them from the text's essential semiotic structure. Placing various elements of the myths or social customs from non-Western early cultures into the essential structure has enabled Lévi-Strauss to reach the conclusion that those elements that have been generally deemed "primitive" or "savage" by European contemporaries are in fact functionally identical to those in "civilized" societies (Lévi-Strauss, 1963 [1958], 1966 [1962], 1976 [1973]). The process of revealing the text's essential structure, therefore, can consequently extract social factors that socially oriented analysts are interested in.

In this paper, the major issue with the Swalean approach is identified as the lack of a solid identification method for the generic structure. For this missing methodological ground, the adoption of the Greimassian deductive approach is proposed. The argument is that despite the theoretical disparities between these two approaches, the issues with the Swalean approach can be neatly resolved by reducing the CARS components into the minimal units of signification and considering the relations between the components in a similar way as Greimas (1983 [1966]) did when looking at Propp's (1968 [1927]) folklore generic structure model.

\section{The CARS model}

\subsection{Background}

Swales (1990) defined genre as follows:

[It] comprises a class of communicative events, the members of which share some set of communicative purposes. These purposes are recognized by the expert members of the parent discourse community, and thereby constitute the rationale for the genre. This rationale shapes the schematic structure of the discourse and influences and constrains choice of content and style. (Swales, 1990, p.58)

Based on this definition, Swales's schematic structure places its rationale on communicative purposes shared by the members of the community. To identify genre membership, Swales (1990) proposed to rely on the concept of prototypicality (Rosch, 1975). Further, drawing on the concept of family resemblance (Wittgenstein, 1958), Swales (1990, p.49) pointed out that instances of genre resemble each other while varying in their prototypicality and that genre is identifiable regardless of its variations between instances. The prototype model of categorization is a cognitive-based categorization approach formulated originally by Rosch (1975). Prototypes of categories are explained as "clearest cases of category membership defined operationally by people's judgments of goodness of membership in the category" (Rosch, 1978, p.36). In the application of the prototype theory to linguistics studies, four features are recognized as typical of prototypicality:

First, prototypical categories exhibit degrees of typicality: not every member is equally representative for a category. Second, prototypical categories exhibit a family resemblance structure, or more generally, their semantic structure takes the form of a radial set of clustered and overlapping readings. Third, prototypical categories are blurred at the edges. Fourth, prototypical categories cannot be defined by means of a single set of criterial (necessary and sufficient) attributes. (Geeraerts, 2010, p.187) 
As Posner (1986) pointed out, and as emphasized by Geeraerts (2010), the interrelationships between these four features reveal that prototypicality is itself a "prototypical concept", i.e. not all of the features listed in the quotation necessarily cooccur.

Swales' (1990) genre theory follows prototype theory in that category boundaries are flexible and that categories have non-equal, internal structures, whose memberships are characterized by different degrees of centralness. Swales (1990, p.49) further explained that the central genre membership can take the definitional approach, defined by concrete membership features. In contrast, the peripheral membership involves cluster approaches. The basis of the combined identification methods is placed on Armstrong, Gleitman and Gleitman's (1983) integration of definitional and cluster approaches:

There are privileged properties, manifest in most or even all examples of the category; these could even be necessary properties. Even so, these privileged properties are insufficient for picking out all and only the class members, and hence a family resemblance description is still required. (Armstrong et al., 1983, p.270 [cited by Swales, 1990, p.52])

For Swales (1990), communicative purpose serves to be the privileged property of a genre, while categorizing peripheral instances of genre membership becomes possible with a family resemblance description. This is because, although peripheral elements may not share common features with each other, they may still form a family resemblances relationship: "what holds shared membership together is not a shared list of defining features, but inter-relationships of a somewhat looser kind" (Swales 1900, p.49). This lead to a rather optimistic view of categorizing the central as well as peripheral instances of genre with the integration of the definitional and family resemblance approaches:

\footnotetext{
This integration has considerable appeal. It allows the genre analyst to find a course between trying to produce unassailable definitions of a particular genre and relaxing into the irresponsibility of family resemblances. As we have seen, communicative purpose has been nominated as the privileged property of a genre. Other properties, such as form, structure and audience expectations operate to identify the extent to which an exemplar is prototypical of a particular genre. (Swales, 1990, p.52; original emphasis)
}

Apart from the fact that an exact method of identifying family resemblances is not provided in the Swalean literature, the expression "relaxing into the irresponsibility of family resemblances" seems to suggest that the concept of family resemblance in Swalean genre analysis is loosely defined. This over-assurance on the "relaxed" family resemblance approach may be considered one of the causes that the identification of peripheral elements in genre membership poses difficulty with the current Swalean model. The model can hardly identify "other properties" that supposedly operate to tie peripheral exemplars to the genre membership category.

Communicative purpose, "the privileged property of a genre", does not serve as a solid criterion for genre identification either. It is true that, in one aspect, communicative purposes can successfully serve as a primary identification criterion of a genre even with an instance that shares the surface level linguistic features with other genres, because communicative purposes can disentangle, in Swales' (1990) words, "the clever parody from 'the real thing"' (Swales, 1990, p.49).

However, as Swales (1990) conceded, it is also true that "it may be objected that purpose is a somewhat less overt and demonstrable feature than, say, form and therefore serves less well as a primary criterion" (Swales, 1990, p.46). Yet it was claimed that the privilege of communicative purpose could be maintained because "the fact that purposes of some genres may be hard to get at is itself of considerable heuristic value" (Swales, 1990, p.46). However, communicative purpose is placed as an important concept that sets up "a relationship between the purpose accomplished by a genre and the structure of the genre by suggesting that the communicative purpose of a genre (a 'privileged' criterion) shapes the genre and provides it with an internal structure - a schematic structure" (Askehave and Swales, 2001, p.198). This is rather contradictory: the model is precategorized in terms of its surface realizations (detailed in Section 2.3) whereas it is 
communicative purpose that supposedly plays a crucial role in text structuring. The ambiguity involved with communicative purpose and family resemblance, therefore, may be one of the causes that identifying genre elements with the Swalean model remains difficult.

As to the structuralist perspectives toward genre analysis, Swales (1990, p.34) only gave passing remarks as a type of genre analysis that was used for folklore studies. As this present study shows, applications of structuralist analytical methods for genre analysis can serve to provide properties that tie exemplars to the genre membership category. However, the structuralist perspectives have, to my knowledge, never been seriously considered in ESP fields.

\subsection{The history of the CARS model}

The CARS model has gone through a number of revisions. One recurring trend involves its simplification in accordance with generic functions. Early on, in 1990, Swales's original four-move model from 1981 was simplified into the three-move model that came to be known as the CARS model (Figure 1).

MOVE 1:
Establishing a territory
- Step 1: Claiming
centrality
- Step 2: Making topic
generalization (s)
- Step 3: Reviewing
items of previous
research

MOVE 2:
Establishing a niche
- Step 1A: Counter-
claiming
- Step 1B: Indicating
gap
- Step 1C: Question
raising
- Step 1D: Continuing
a tradition

MOVE 3:
Occupying a niche
- Step 1A:
Questioning purpose
- Step 1B: Accouncing
present research
- Step 2: Announcing
principal findings
- Step 3: Indicating
RA structure

Figure 1. The CARS model (based on Swales, 1990, p.141)

In the revised model, Move 1 is known as establishing territory, the rhetorical function of which is to provide a background for research. It is made up of smaller generic structure components called steps, such as claiming centrality, making topic generalization(s), and reviewing items of previous research. Move 2 is known as establishing a niche. Its rhetorical function is to point out a gap in research, and it is made up of steps such as counter-claiming, indicating gap, question raising, and continuing a tradition. In Move 3, research is presented, and hence it is described as occupying a niche. It is made up of steps such as questioning purpose, announcing present research, announcing principal findings, and indicating research article structure.

The CARS model has been widely applied to a number of studies, some of which consequently revealed its inadequacy. For instance, Chu (1996) pointed out the functional similarities between the steps of Move 2. In accordance with this, Swales (2004) revised the model again, with one of the notable changes being that Move 1 and Move 2 are simplified. The revised version of Move 1 has only one step, topic generalization of increasing specificity. Similarly, the steps within Move 2 have been reduced into two, indicating a gap and adding to what is known, with an optional step of presenting positive justification.

Lewin et al. (2001) had also pointed out that the functions of reviewing previous research, which was a step under Move 1 in Swales's original revision, can vary and 
hence citations can occur across moves. Accordingly, Swales's latest model allowed citations to occur in all three moves.

While there have been inclinations to simplify the model, the need to describe the complexity of the structure of introductory portions of academic writing has increased. One of the concerns about complexity is that Swales's original model from 1981 was linearly constrained, as was suggested about Propp's (1968 [1927]) folklore structure model. Another is Samraj's (2002) revelation that the model has many complex embedded moves within moves, which she expressed as the "recycling of moves" where submoves/-steps cyclically occur.

Swales's revised model hence allowed the recycling of Move 1 and Move 2 to produce "increasingly specific topics" (Swales, 2004, p.230). Further, concerning Move 3 , Swales (2004, p.231) pointed out, "[It] can now be seen as typically more complex and elaborated than originally envisioned," about which he contemplated, "It remains unclear whether this is the result of evolution in the genre itself or of further studies, or perhaps both." The complexity partly has to do with just that: Move 3, announcing present research, is often presented with a mixture of elements, such as announcing methods, defining terms, and so on (Chu, 1996; Anthony, 1999; Dressen and Swales, 2000). Hence, the revision that has been made to comprise the complexity of Move 3 involves setting up one obligatory step, announcing present research descriptively and/or purposively, with the three optional steps of presenting research questions or hypotheses, definitional clarifications, and summarizing methods (Swales, 2004, p.232). Further, in the revised model Move 3 has three steps: probable in some fields: announcing principal outcomes, stating the value of the present research, and outlining the structure of the paper (Swales, 2004, p.232). Thus, while attempts have been made to simplify the model on the basis of functional similarities among generic structure components, studies keep revealing variations, consequently making the model more complex.

\subsection{Issues with the CARS model}

The problems with the CARS model can be summarized in two general issues: 1) the inflexibility of its prefixed design, and 2) the lack of reliable identification criteria for generic structure elements. The inflexibility of the model limits its applicability, so that it is only useful for typical traditional research articles, and as such, studies keep finding atypical or new kinds of elements that do not fit into the model. This limitation indicates that the model is hardly able to take account of the evolving academic genre or synchronic variations such as disciplinary and cultural variations.

Because the model is pre-categorized in terms of its surface realizations, studies that find elements that do not fit into the model need to add new subcategories to the model. Samraj (2002, p.1), for instance, found that the introductions of texts in the field of conservation biology "tend to justify the research being reported in terms of real world matters rather than the epistemic world of research"; hence Samraj (2002) added the more delicate generic structure subcategories claiming centrality in research (Move 1), claiming centrality in the real world (Move 1), indicating a gap in research (Move 2), and indicating a gap in the real world (Move 2) to the model.

This further relates to the second issue with the CARS model: the lack of reliable identification criteria. Lorés $(2004$, p.282) pointed out that "the analysis of the research genre seems to lack uniform standards for move identification, as they include not only lexicogrammatical features but also cognitive criteria." Swales (2004, p.229) himself conceded that "the identification of moves, and consequently the setting of move boundaries, is established by a mixed bag of criteria." One of the consequences is that newly encountered surface realizations escape being identified as merely a different realization of the same function that was previously identified. A criticism has been that Swalean prototype-based understanding of genre consequently leads analysts to rely on intuition; that is, analysts are led to classify generic structure elements according to what came up in their mind when reading the text (Crookes, 1986; Lorés, 2004). 
The relation between linguistic realization of a move and its rhetorical function has not sufficiently been explored. Lewin et al. (2001, p.18) pointed out that "Swales (1990) appears to combine criteria from different systems. For instance, he distinguishes Move 2 (establishing the niche) by either lexicogrammatical criteria, such as negation in the determiner, or by rhetorical function such as "logical conclusions." As reviewed earlier, Lewin et al. (2001) further expanded on the issue of the classification of "reference to literature" as a separate move:

The assumption that 'reference' in itself conveys communicative intent, in the same way that the other rhetorical functions do, seems ill-advised. While Swales (1990) no longer categorizes literature references as a separate move, his original (1981) position influenced subsequent studies (e.g. Crookes, 1986). (Lewin et al., 2001, pp.25-26)

The lexicogrammatical criterion has also been questioned by Chu (1996):

[Swales] also maintained that words such as suffer, is limited to, time consuming, expensive and not sufficiently accurate are indications of gaps of some kinds. However, these lexical items can also be interpreted as inherent problems of the previous methods rather than gaps to fill, and thus can be seen as counter-claims of various sorts (Chu, 1996, p. 11; original emphasis; cited by Swales, 2004, p.230).

Lexicogrammar may indicate possible generic structure components, but that alone doesn't determine the rhetorical function of the component. Swales' later work from 2004 attempts to clarify his position toward such issues. As to the lexicogrammatical identification of moves, he noted:

Sometimes, however, grammatical features can indicate the type or nature of a move. ... Additionally, there are many types of lexical signal. Some are obvious enough ("The main methods used were...; The result are shown in Table 1"); others can be a little more subtle, such as indications of the end of a move by the use of phrases such as "in conclusion" or "in summary." (Swales, 2004, p.229; original emphasis)

Swales appears to be leaning toward function for the identification of moves but leaving the complexity of generic structure to the ambiguity of family resemblance, without establishing a clear identification method that can provide help in sorting out the issues. Hence, the original goal of identifying the peripheral elements with the family resemblance approach has not been achieved.

\section{Method}

To help resolve the issues described in the previous section, I propose integrating the structuralist approach into the CARS analytical process, so that the observed surface complexity noted in the literature can be neatly sorted out. The textual materials investigated for this purpose are introductory chapters from $\mathrm{PhD}$ theses in the discipline of History recently produced in Australia. Humanities theses can become an ideal site of investigation because they have been widely reported to be diverse in their ideological orientations as well as their textual presentations (cf. Hall, 1985; Hodge, 1995; Paltridge, 2002; Swales, 2004). Variations within one discipline are explored so that various research justification strategies where the disciplinary purpose is fairly uniform can be highlighted. The discipline of History has widely been reported to be diverse due to various ideological factors (cf. Jordonova, 2000; Bondi, 2005; Anderson and Day, 2005), and is therefore appropriate for the present purpose to investigate how integrating the structuralist method into the CARS model facilitates generic structure analysis of texts that contain the variety of research writing strategies.

More specifically, the Greimassian approach of text analysis is employed, having in mind the way that Greimas (1983 [1966]) reduced Propp's (1968 [1927]) 31 functions in Russian folktales. Both Greimas and Propp took the structuralist approach to generic structure analysis, but Greimas's model radically reduces the generic structure elements into pairs of oppositions. The model was designed in response to Lévi-Strauss's (1984 [1960]) criticism of Propp's model for not reducing elements to the minimal analyzable 
units of meaning or considering the relationships between generic structure elements. The issues with the CARS model appear to be a comparable under-reduction of the generic structure components and hence have the potential to be resolved in a similar way.

In the Greimassian generic structure analytical model, a text is made up of axiological elements, which means that various axes of binary structure constitute a text. In this study of the generic structure analysis of introductory chapters of theses, the axis is placed on the binary structure " $\mathrm{x}$ warrants $\mathrm{y}$ ", where $\mathrm{x}$ represents a semantic role of Agent/Cause, while y represents Research. The verb warrants is used following the coinage of the term by Hood (2010). Hood (2010) observed that the rhetorical function of personal anecdotes in academic writing can be said to provide a "research warrant" similar to the typical research-justifying strategies, although it was beyond the scope of her study to place such elements in a generic structure model. In the present study, therefore, Move 1, Move 2, and other atypical realizations of research-warranting strategies can be placed on $\mathrm{x}$, while Move 3 can be placed on $\mathrm{y}$. The function of Move 1 is to increase the value of research by claiming its centrality, and of Move 2, to increase the value by indicating the gap that the research needs to fill; hence, they both warrant research albeit by different semantic strategies. Therefore, Move 1, Move 2, and atypical research warranting can be reduced to the same unit, which forms a functional opposition to Move 3.

The Semiotic Square is a method that lucidly describes the relationship between semiotic elements, which represents the semantic articulation on the content plane (Greimas, 1983 [1966]). The basic Semiotic Square used for this study is shown in Figure 2.

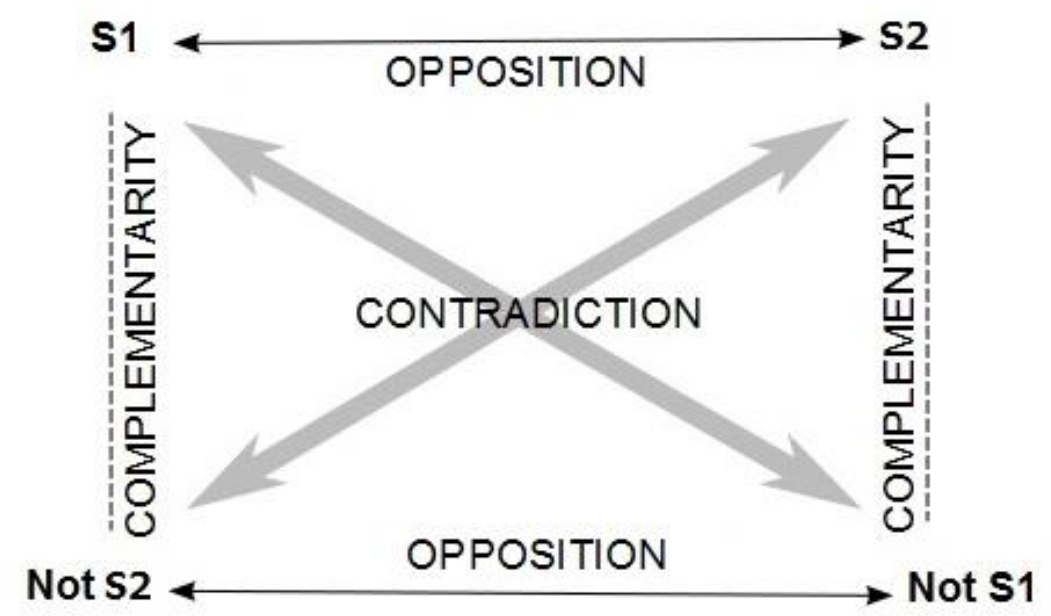

Figure 2. Basic Semiotic Square (based on Greimas 1983)

In Figure 2, four semes (semiotic elements) are displayed on the square, with $S 1-S 2$ and Not S1-Not $S 2$ being in opposition to one another. S1-Not S1 and S2-Not S2 contradict one another. Not $S 1$ can be $S 2$ or something other than $S 1$; similarly, Not $S 2$ can be $S 1$ or something other than $S 1$.

The Semiotic Square that represents the revised CARS model for this study is displayed in Figure 3. 
S1:

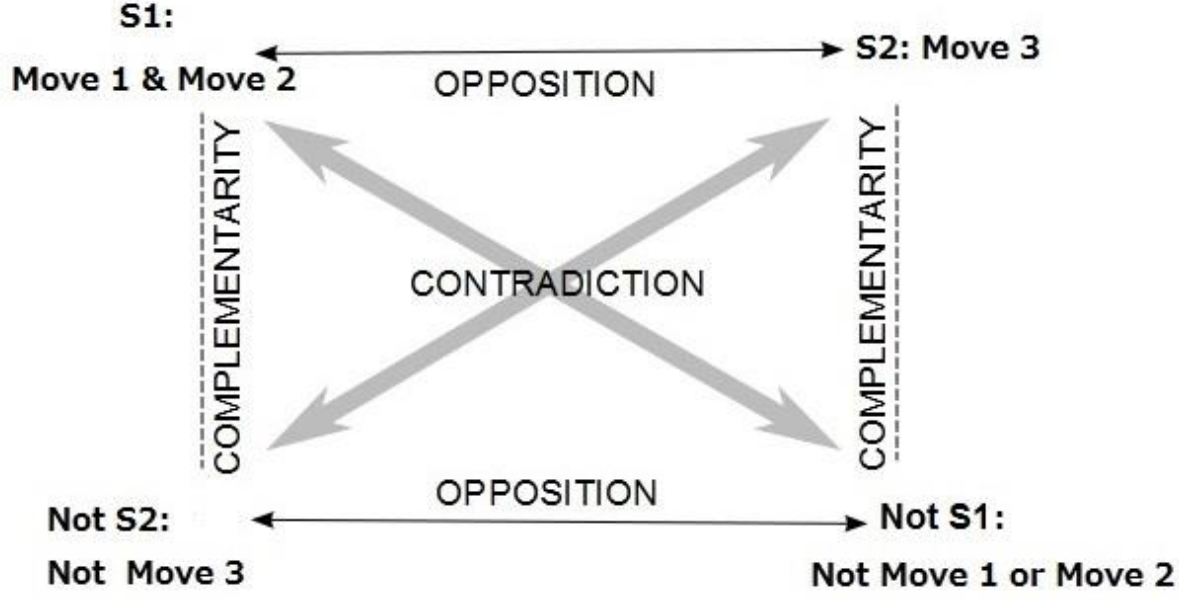

Figure 3. Semiotic Square for Moves in the (revised) CARS model

In this study, the typical generic structure elements of the CARS model are placed on the top level of the square. $S 1$ represents typical research warranting strategies (Move 1 and Move 2), which is in structural opposition to $S 2$, research to be warranted (Move 3 and Not Move 1 or Move 2). Not $S 2$ is in a position for atypical research warranting strategies that do not exactly fit into Move 1 or Move 2. Not S1 (Not Move 1 or Move 2) is a position for atypical Move 3-like elements that are warranted by S1 (Move 1 and Move 2) or Not S2 (Not Move 3: atypical research warranting strategies).

The Semiotic Square enabled Jackson (1998) to describe both the differences and similarities between clear and unclear legal cases. Among semiotically oriented genre analysis using the Semiotic Square, Jackson's study (1998) on legal discourse may provide a good example of the application of the Semiotic Square for those from ESP backgrounds who are unfamiliar with it. In a lawsuit to determine whether the defendant is guilty (S1) or innocent (S2), it is not, in reality, always clear whether the defendant is actually guilty or innocent, as there may not be enough evidence to determine it clearly. Being found not guilty, therefore, does not necessarily mean that the defendant is innocent. Jackson investigated this unclear nature of giving verdicts in a lawsuit using the Semiotic Square. One of the models Jackson (1998, p.238) displayed reads as follows: S1: found guilty; S2: found not guilty; Not S1: not found guilty; Not S2: not found not guilty. He pointed out that, for a layperson, not guilty means innocent, partly because the layperson tends to construct meaning in terms of binary oppositions, namely, guilty v. innocent. So, the verdict not guilty would be perceived as innocent on the basis of this opposition without leaving room for the second level of the Semiotic Square that indicates that the defendant is possibly guilty or innocent. Instead of unclear cases being rigidly placed into a pre-established category (using the first level of the square only), the second level of the square can flexibly identify the function of a newly encountered set of realizations. In the present study, it is revealed that atypical elements observed in the corpus that would have difficulty fitting into the CARS model, historical recount, ${ }^{1}$ personal anecdotes, and recount as observer, can all be placed in the Not S2 position, demonstrating that these atypical elements can be reduced into the unit of research warranting. ${ }^{2}$

\footnotetext{
${ }^{1}$ Recount is a generic structure component labelling in systemic functional linguistics (SFL; cf. Coffin, 2010, Martin and Rose, 2008).

${ }^{2}$ The functional roles in the Greimmassian framework are called actants, and the system and realizations are integrated with them.
} 
The analysis will move on to show more precisely how this semiotically oriented method can lucidly identify the function of discourse that has so far been seen as being complex. Using instances from the present corpus, the analysis will demonstrate that the surface lexicogrammatical/semantic features as well as the recycling of moves can be sorted out into the simple binary structure.

\section{Analysis}

\subsection{Historical recount}

Historical recount may be an example that is specific to the discipline of History, which is exemplified by its narrative-like elements (see Bondi's [2005] study on the abstracts of history papers). Excerpt (1), taken from a thesis about Frank Berryman, an Australian lieutenant general from World War II, represents such historical recounting.

(1) The day was dark and overcast, a remnant of the typhoon that had delayed the impending proceedings for the previous two days. Fifty senior military officers lined up on the open quarter deck of the USS Missouri. Surrounding them on every vantage point, were the officers and sailors of the Missouri as well as camera men and reporters. ... Directly behind the Supreme Allied Commander, General Douglas MacArthur, and squeezed between Lieutenant General K. N. Derevyanko of the Soviet Union and Colonel L. Moore Cosgrave of Canada stood the Australian Commander in Chief, General Sir Thomas Blamey. Lieutenant General Frank H. Berryman, the Australian Army representative to the surrender of Japan and Blamey's most trusted subordinate stood immediately behind his commander in chief. (Dean, 2007, p.1)

In the CARS model, while not explicitly claiming centrality, cases such as that in excerpt (1) may be closest to Move 1, for they recount the event the thesis will proceed to give an historical account of and thus provide background knowledge for research. However, its difference from the typical Move 1, in which it is marked as a narrative without any direct claims of the relevance of research, will be lost if classified as Move 1. The complexity can be sorted out by placing historical recount on the Not $S 2$ position on the Semiotic Square (Figure 4). By this stage, the semiotic status of historical recount is clear. The function of historical recount is complementary to Move 1 and Move 2, both of which are in structural opposition to Move 3 and Not Move 1 or Move 2.

S1:

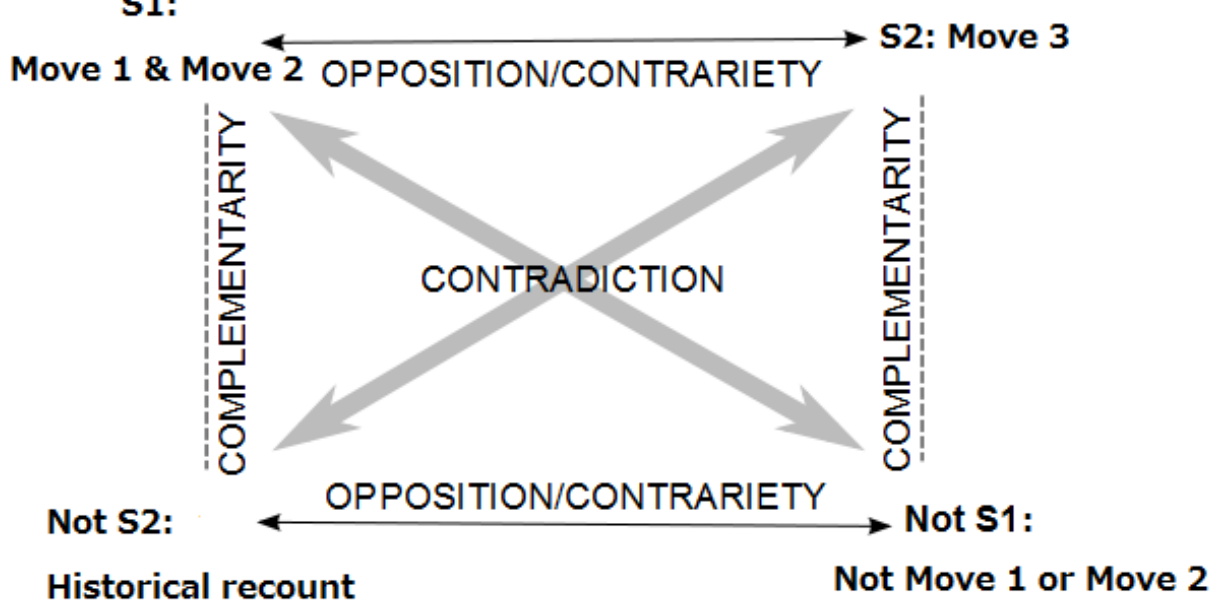

Figure 4. Semiotic Square: Historical recount in relation to other moves 
Within the tradition of the CARS model, a possible treatment made with such a case as the one described in the excerpt would be to set up another step in Move 1, which could be termed something like "giving background by recounting historical event." However, that would add another complexity to the model and obscure the essential function of the excerpt in relation to the whole introductory chapter.

\subsection{Personal anecdotes}

The following excerpt appears early in the introductory chapter of a thesis in the field of "participant history", where the author attempts to write a history of the Australian Labor Party as a participant historian:

$$
\begin{aligned}
& \text { Like many of my political generation, my own development of a 'primal } \\
& \text { socialist innocence', really began at university. I went to the Australian } \\
& \text { National University at the beginning of } 1966 \text { having been brought up in a } \\
& \text { country town (Orange) as the child of parents who typified the post-World } \\
& \text { War Two middle class. My father had come from a working class } \\
& \text { background and left school to work in the 'woollen mills' at Orange before } \\
& \text { fleeing the certainties of factory labour (in a reserved occupation) to enlist in } \\
& \text { the Second AIF. A prisoner of war after the fall of Singapore, he returned } \\
& \text { home after the war and built a successful small business as a contract painter. } \\
& \text { My mother also came from a rural working class background and met my } \\
& \text { father after the war on a bus on a hockey trip to Dubbo (they were both } \\
& \text { hockey players)...I was interested in politics at my local high school and my } \\
& \text { memory is that it predisposed me to a more Left wing sensibility than that } \\
& \text { suggested by the more conservative political environment around me. This } \\
& \text { was a town that was part of Country Party electorates, state and federal, } \\
& \text { during the dominant anti-communism of the 1950's and early 1960's, though } \\
& \text { my father mostly voted Labor and my mother always did. (Harris, 2002, p.6) }
\end{aligned}
$$

Excerpt (2) represents typical postmodern and poststructuralist problematizations of representation and meaning (cf. Hall, 1985; Hodge, 1995). A semantically oriented description of it may be "giving autobiographical recount," but that does not place it in a clear position within the semiotic spaces between the generic components. The excerpt has the function of preparing to introduce its Move 3, research, for the discourse. In comparison to typical traditional History discourse, the excerpt could be regarded as a personal narrative influenced by the postmodern turn in history:

\footnotetext{
Since the research is classified as a participant history, the author [Harris] considers introducing the history of his own life in the introduction to be an important step to introduce the history of his life in the introduction, so that he can explain how he - a participant historian - has been brought up to have a particular political view and, consequently, to be involved in the political movement he is going to research. More than being simply autobiographical, the excerpt is carefully crafted, starting with, "Like many of my political generation, my own development of a 'primal socialist innocence', really began at university...," thereby bridging the shift between what so far has been presented in the chapter and the autobiographical recount. (Sawaki, 2014, p.185)
}

The items to be recounted are carefully selected so that the narrative gradually moves on to an account of why the author has come to be interested in politics and to be involved in a political movement. The excerpt is preparing to introduce the main part of the discourse, the new research. Hood (2010, p.46) similarly identified the rhetorical function of the personal anecdotes in research articles in the field of cultural studies: "[They] function to establish the significance of the object of study, and contribute in similar ways to the construction of the research warrant."

Within the CARS model, excerpt (2) can be categorized as either Move 1 or Move 2 because it prepares for Move 3. Some may classify it as Move 1 because it in some ways provides background information for the new research; however, it keeps some 
distance from a prototypical realization of Move 1, the purpose of which is to establish a territory by claiming that the area is important. Some others may identify a Move 2-like feature in this excerpt in that it builds the tension that triggers the new research. However, this is somewhat implicit and is far from the prototypical Move 2 strategies of expressing the author's own opinions about the need for the current research.

Most importantly, however, when considering the relations between the generic components, the excerpt functions to push forward Move 3. Thus, the status of personal anecdotes on the Semiotic Square can be summarized similarly to the other components that prepare for research, occupying the Not S2 position (Figure 5). Hence, the function of personal anecdotes is complementary to Move 1 and Move 2, both of which are in structural opposition to Move 3 and Not Move 1 or Move 2.

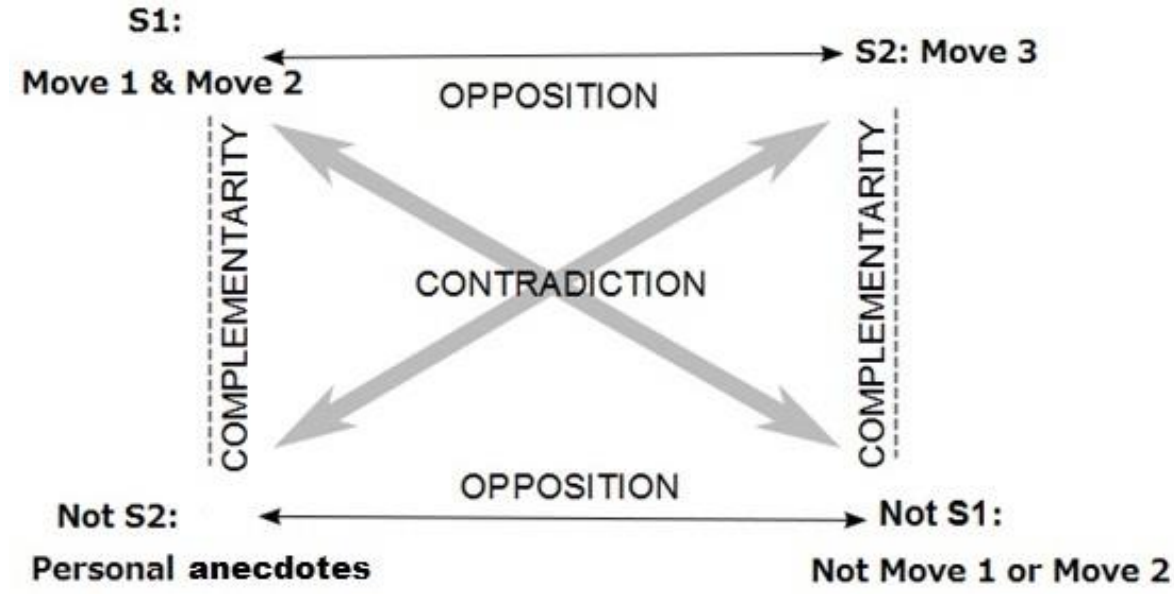

Figure 5. Semiotic Square: Personal anecdotes in relation to other moves

\subsection{Recount as observer}

Another type of component whose status can be clarified by using the Semiotic Square is recount as an observer. The following excerpt is from a thesis that explores the impact of migration on Papua New Guinea. To recount the carnival scene in Papua New Guinea, the author uses a reporting style that represents the nation's rapid immigration and multicultural atmosphere:

(3) It's Carnival time - the costumes are bright, the dancers gyrating, the music lively. However, this is not the famous Rio Carnival, or even the Notting Hill Carnival in London (which had Unity and Diversity as the 2005 theme), but the Wamena Carnival in Papua. This town in the highlands of Indonesia's easternmost province is celebrating its diversity with a parade through the town. The costumes are traditional dress from the different ethnic groups that make up the area's population - indigenous Dani and Lani, Javanese, Bugis, Torajan, even a lone girl from Timor. The dancers include two Papuan boys dressed only in penis gourds doing sexy gyrations on top of a mini-bus to the blaring dangdut music. Is this an exhibition of the cultural exchange occurring in this distant outpost, the multicultural nation in action? A celebration of the diversity in the unity? (Upton, 2009, pp.14-15)

By reporting how multicultural the carnival scene is, the excerpt functions to prepare for introducing the research in that the author's research topic is to observe the alteration of Papua New Guinea's society due to rapid immigration. In the traditional Swalean framework, this excerpt may be close to Move 1, establishing territory, because it depicts the mixing of people in Papua New Guinea's society, which relates to the author's research. However, it seems to be a far distance from the typical way of establishing a 
research territory in that the excerpt only reports the carnival scene and does not explicitly establish a research territory. It is functionally complementary to Move 1 and Move 2 in that it prepares for research. Hence, recount as observer also occupies Not S2 position on the Semiotic Square (Figure 6). The function of recount as observer is complementary to Move 1 and Move 2, forming a structural opposition to Move 3 and Not Move 1 or Move 2.

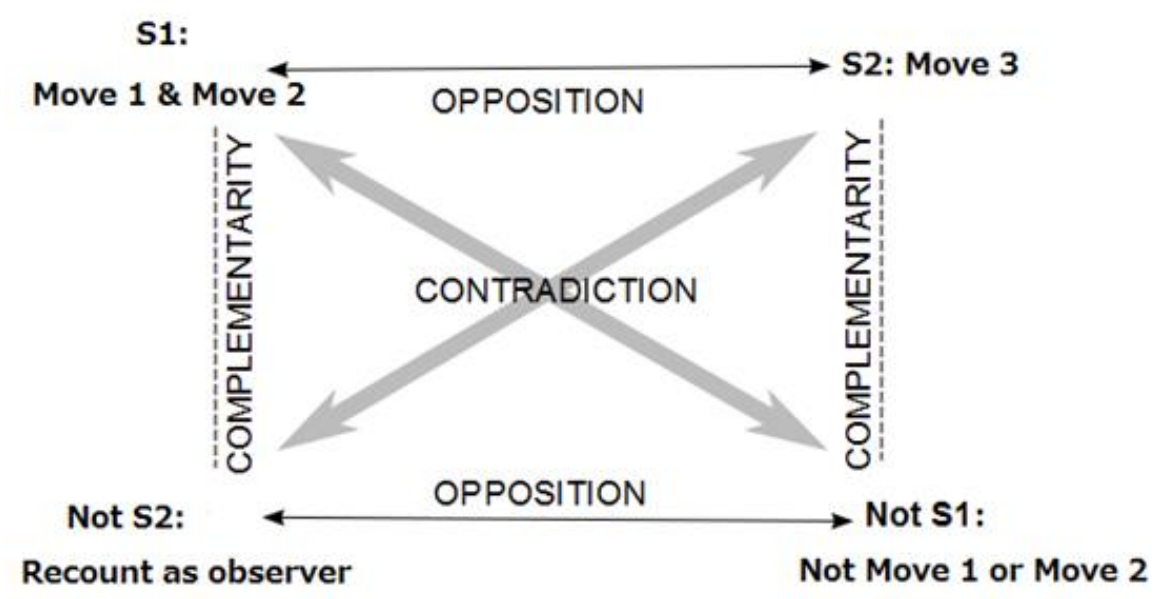

Figure 6. Semiotic Square: Recount as observer in relation to other moves

\subsection{Semiotically oriented identification of generic structure elements}

The following excerpt presents an example of the complexity in the identification of generic structure elements that is due to the combined cognitive and lexicogrammatical/semantic identification criteria within the CARS model. The thesis it is taken from is about the African American Conservative movement in modern America, and the excerpt is concerned with the problems and difficulties that African Americans have faced in American history. Excerpt (4) alone may resemble Move 2, for it indicates a gap in the real world (Samraj, 2002) as it lists negative situations that African Americans have faced.

(4) Nobody can possibly dispute the fact that the black conservatives have had a significant impact on this 'culture'. Indeed, for much of the 1980s and 1990s, these intellectuals were ensconced at the heart of the national dialogue on 'race', tapping into the enduring American philosophies of individualism and free enterprise, seeking to overturn the corrective political initiatives secured by the great civil rights movement. Insisting that their differences were not with the goals of freedom, justice and equality, but with the methods employed to achieve them, black conservatives argued that the liberal policies associated with the 'Great Society' of the late 1960s had failed, that government, far from providing the solutions, was in fact exacerbating the problems faced by African American people. Paying special attention to the controversies surrounding affirmative action, welfare and public education, they turned the language of the 'left' on itself, charging liberal leaders black and white - with re-enslaving black people on new plantations of government dependency. ...

How exactly is one to understand these negative black perceptions of government's attempts to help black people? A cursory glance at the contemporary origins of black conservatism provides some clues. It is now 
widely acknowledged that as the American conservative movement gathered momentum in the 1970s, 'a swarm of new, self proclaimed black conservatives...took flight,' subsequently emerging as a visible intellectual bloc in the wake of Ronald Reagan's landslide election victory of 1980. (Ondaatje, 2007, pp.2-3)

Using the current CARS components identification method of combining cognitive and lexicogrammatical/semantic criteria, analysts would find it difficult to capture the function of the excerpt. This is because its function is not immediately clear when trying to rely on the cognitive criteria. When trying to rely on lexicogrammar and semantically negative descriptions, such as negations (Swales, 1990), the excerpt may appear to be Move 2. It is important that along with many descriptions of negative situations related to African Americans, the previous excerpt above could not be classified as Move 2 unless the purpose of the text were to take part in resolving such issues; namely, to fill the gaps. This is not, however, the issue that the thesis is trying to resolve. This is made clear in the excerpt (5), which appears a bit earlier in the text.

\begin{abstract}
While these black conservatives' 'existence' has continued to stir emotions and provoke polemical debate [Move 1] serious scholarly studies of their social and political thought remain elusive. [Move 2] By focusing on these intellectuals' ideas and assessing them alongside mainstream scholarship, this thesis seeks to fill an important void in the literature on a most intriguing impulse within the contemporary American political culture. [Move 3] (Ondaatje 2007, p.2; move numbers added)
\end{abstract}

Hence, with a larger functional picture in mind, it becomes clear that the excerpt (4) is not Move 2. Describing problems in the external world with negations does not automatically equate with a Move 2 component. Within the CARS model, the excerpt would be closest to Move 1 because it in some way provides background for the research topic. Hence, the excerpt warrants research. The different strategies to realize research warranting, such as Move 1 and Move 2 also, can be confirmed only in terms of their relationship with other parts of the text.

\title{
4.5. Aspectual moves
}

Many of the theses observed exhibit what has been termed in the literature as cyclical moves or submoves/-steps (Ahmad, 1997; Dressen and Swales, 2000; Samraj, 2002). These processes are embedded within the move of a specific topic concerning an object of study, methodology, and so on, and it is in these areas that they form cyclical moves. By reducing such elements to the minimal units, however, the present study classifies them as independent elements. The following excerpt is from the participant history thesis introduced earlier, which claims the relevance of using "two voices":

(6) It is quite common for writers in the fields of history and memory to be "an autobiographical presence in their work". Sometimes this presence is quite overt, particularly in the case of the 'participant historian'. For example, when writing about the anti-war movement of the late 1960's, Ann Curthoys chose to use two voices: one the detached voice of the historian and the other, a personal narrative explaining her own involvement and feelings. [Submove: Move 1] As this thesis is also a participant history I have, like Curthoys, chosen to use two voices. I have written this introduction in the first person, incorporating my own life history into a discussion of the methodology of this study, particularly as regards the relationship between memory and history. The thesis proper will follow the more detached voice of the historian with my own participation referred to in the third person and, 
where necessary, additional comments or references provided in the footnotes as 'the writer'. [Move 3] (Harris, 2002, p.8; move numbers added)

Based on the conception of submoves, the entire excerpt (6) would be classified as Move 3 , as it is concerned with the voices or perspectives used in the thesis. The first part of the excerpt, up to "her own involvement and feelings," would be considered to be a subordinate Move 1 element embedded within Move 3; hence, such a Move 1 element is treated essentially as Move 3. Alternately, the previous framework might add a new step to Move 3, self-reference, in the same way that the CARS analysis for thesis study tends to add more and more steps in Move 3 (cf. Bunton, 2002).

However, it is important to note that the former part of the passage functions to prepare for the latter part, by claiming the relevance of writers in the work in the field of history and memory to maintain an autobiographical presence. Although it is possible to see these as independent generic structure elements, semiotically, these elements form structural oppositions to each other, and none of them are subordinate to another. It should be emphasized that there is no essential functional difference between generic structure components of different semantic aspects of research; for example, between the way centrality is claimed in research and the way it is claimed in method/materials/writing style. And yet, in the CARS framework, only claiming centrality in research has been identified as Move 1. In order to resolve such mixing of essential functions, the primary identification criterion should be set as the essential relations between generic structure elements. Hence, the first and latter parts of the excerpt (6) are reduced to the structural oppositions between research warrants and research, with semantically oriented description of self-reference.

\section{Discussion}

The analysis conducted in this study has shown that it was not the preset categories in the CARS model but the flexibility in the structuralist analytical methods that have provided an exact method of identifying generic elements. The fact that various surface-level realizations were neatly sorted out by setting a simple binary opposition structure of " $x$ warrants y" indicates that all those seemingly different strategies serve to achieve the same rhetorical function, research warranting. Not only does it mean that atypical realizations of research warranting can be analyzed but also that Move 1 and Move 2 in the CARS model can be placed under the same umbrella. The elements in the text that can be placed under this umbrella all increase the value of research, albeit by different strategies.

This indicates that, from the perspective of prototype theory, Move 1 and Move 2 are the central members of the category, whereas the atypical elements observed in the present analysis are peripheral members. This accords with Swales' original descriptions of genre membership in that "what holds shared membership together is ... interrelationships of a somewhat looser kind" (Swales, 1990, p.49), because while the atypical elements observed may not share definitional criteria with Move 1 and Move 2, they all hold inter-relationships. Hence, the ambiguities caused by "relaxing into the irresponsibility of family resemblances" (Swales, 1990, p.52) can be avoided, while classifying less prototypical instances of genre can at the same time be accommodated.

For those applying this generic-structure analytical method for the study of the introductory portions of academic discourse, the binary structure of " $x$ warrants $y$ " can be deployed as the essential structure. It may not be appropriate to use terms such as Move 1, Move 2, and Move 3 because they do not belong to the same structural level, and using terms that belong to different levels may hinder the analyst from identifying the minimal unit of signification. Hence, if surface-level descriptions are required, the analyst may first describe the aspect of the research (i.e. warranting method), for which a corresponding element (i.e. research method) should be found in the text. Then, depending on the purpose of research, further delicate realization patterns may be 
described. For instance, pedagogically motivated research may need to distinguish between claiming relevance and pointing out a gap to be filled, then the description can go on such as "warranting method by pointing out a gap to be filled with the previous methodology". Further, if the gap in methodology is pointed out by reviewing methodological issues with the previous literature, the analysis may decide to go on describing, "warranting method by pointing out a gap to be filled with the previous methodology by reviewing literature". Such descriptions may continue as the semantic properties of the text being analyzed become more detailed. It is important, however, that no matter how long the analyst decides to describe the surface-level realizations, the understanding that all the strategies described contribute to the realization of the rhetorical function of a minimal unit needs to be maintained. This is because, as demonstrated in the present analysis, a rhetorical function cannot be subordinate to another. By producing a single minimal unit that shares a functional relation to the other corresponding unit in a binary model, the model is simplified and unified in a functional classification.

This relational perspective to genre analysis can ease the difficulty for many analysts relying on intuitions; namely, what comes up in their mind at the time of reading the text. The status of a generic structure component can hardly be clear to analysts in isolation from the rest of the text because it is confirmed only when they have gone through the other parts of the text. Greimas (1971) emphasized that there are no rules concerning, for instance, the realization of the component's function in relation to other parts of text based on the types of participants within a unit: Any semantic participants and processes can realize a particular functional unit in discourse. A generic structure component is no more than a part of a structure of signification and can, therefore, be described only in relation to the other components in the text.

By not relying on preset categorizations as an approach, there emerges a potential to determine quantitatively which generic structure components are typical or atypical in the corpus after the entire analysis. If the quantitative result reveals that some newly identified component is replacing the typical traditional realizations of a rhetorical function, it may be that the genre is evolving in such a way as to replace a traditional realization of it. Thus, the evolutional status of atypical generic structure components can be quantitatively determined and discussed in relation to genre evolution and variations within discourse communities. Such a method of identifying the differences from as well as the similarities to the typical generic structure components can be conducted so that all the interesting trends, features, and implications that the corpus contains for genre theory will not disappear during the analytical processes but rather become highlighted.

As Martin and Rose (2008) pointed out, the concept of genre in ESP tends to be treated in contradictory ways in terms of describing the mixture of atypical realizations in academic texts. ${ }^{3}$ As this study has shown, these seemingly different genre elements in a text in fact have an equal semiotic status of research warrants, which itself serves to be indicative of a research genre. As has been demonstrated in this study, consistent rationales for genre analysis in ESP may be achieved by integrating the structuralist perspective.

\section{Conclusions}

Theoretical discrepancies exist between different approaches to genre study; however, as this study has demonstrated, an integral approach has a potential to resolve various issues. Faith in a particular theory may exist with analysts, but it may be necessary to explore

\footnotetext{
${ }^{3}$ Concerning the trend in genre analysis in the ESP tradition that sees such diverse elements in a text as "mixed genre" (cf. Bhatia, 1995), Martin and Rose (2008, p.242) pointed out that "the concept of "mixed genre' is itself contradictory, since recognizing such phenomena entails acknowledging the typologically distinct systemic categories we find in our mix."
} 
various perspectives, because, as a result of exploring what works in real-text analysis, a new theory may follow. This study did not extend to the existing generic structure theories of semiotics nor did it extend the discussion on theoretical matters, such as the relations between "deep structure" and schematic surface structure. Many genre analysts of academic discourse may perhaps prefer to consider that there is something like an overarching move, under which Move 1, Move 2, and other atypical realizations of research warranting fit in, which then forms a structural opposition to Move 3 . While this present study provided evidence from a semiotically-oriented perspective that research warranting can serve as an overarching category for the CARS model, future research may explore it in relation to prototype theory.

Much more research on real text is required to make comments on such matters. Hence, while this study is limited in scope, further potential can be explored of other parts and types of academic discourse through the integration of semiotic perspectives in the future. Most importantly, it is necessary to extend the applicability of semiotics, which, regrettably, tends to be thought of in the neighboring disciplines as not being as useful as it actually is. This would allow for the potential of semiotics to be fully explored and for many applied fields of research concerned with signification to benefit from the wealth of research in semiotics.

\section{Acknowledgements}

I would like to thank the two reviewers of Public Journal of Semiotics for their insightful comments.

\section{References}

Ahmad, U. (1997). Scientific research articles in Malay: A situated discourse analysis. Ann Arbor, MI: University of Michigan PhD thesis.

Anderson, C, \& Day, K. (2005). Purposive environments: Engaging students in the values and practices of history. Higher Education, 49(3), 319-343.

Anthony, L. (1999). Writing research article introductions in software engineering: How accurate is a standard model? IEEE Transactions on Professional Communication, 42(1), 38-46.

Armstrong, S., Gleitman, L., \& Gleitman, H. (1983). What some concepts might not be. Cognition, 13, 263-308.

Askehave, I., \& Swales, J. (2001). Genre identification and communicative purpose: a problem and a possible solution. Applied Linguistics, 22(2), $195-212$.

Bhatia, V. (1995). Genre-mixing in professional communication: The case of 'private intentions' v. 'socially recognized purposes.' In P. Bruthiaux, T. Boswood and B. Babcock (Eds.), Explorations in English for professional communication, (pp. 119). Hong Kong: City University of Hong Kong.

Bondi, M. (2005). Metadiscursive practices in academic discourse: Variations across genres and disciplines. In J. Bamford and M, Bondi (Eds.), Dialogue within discourse communities: Metadiscursive perspectives on academic genres, (pp. 330). Tübingen: Niemeyer.

Bunton, D. (2002). Generic moves in PhD thesis introductions. In J. Flowerdew (Ed.), Academic discourse, (pp. 57-75). London: Pearson Education.

Bloor, M. (1998). English for specific purposes: The preservation of the species (some notes on a recently evolved species and on the contribution of John Swales to its preservation and protection). English for Specific Purposes, 17(1), 47-66.

Chu, B. K. (1996). Introductions in state-of-the-art, argumentative, and teaching tips TESL journal articles: Three possible sub-genres of introduction? City University of Hong Kong, Research Monograph, 12, 1-103. 
Coffin, C. (2010). Historical discourse: The language of time, cause and evaluation. London: Continuum.

Cope, B., \& Kalantzis, M. (1993). Introduction: How a genre approach to literacy can transform the way writing is taught. In B. Cope and M. Kalantzis (Eds.), The powers of literacy: A genre approach to teaching writing (pp. 1-21). London: Falmer Press.

Crookes, G. (1986). Towards a validated analysis of scientific text structure. Applied Linguistics, 7(1), 57-70.

Dean, P. (2007). "The making of a general: Lost years, forgotten battles"; Lieutenant General Frank Berryman, 1894-1941. Sydney: University of New South Wales $\mathrm{PhD}$ thesis.

Dressen, D \& Swales, J. (2000). Geological setting/cadre geologique in English and French petrology articles: Muted indications of explored place. In A. Trosborg (Ed.), Analysing professional genres, (pp. 57-76). Amsterdam: John Benjamins.

Geeraerts, D. (2010). Theories of lexical semantics. Oxford: Oxford University Press.

Greimas, A. J. (1971). Narrative grammar: Units and levels. Modern Language Notes, 86(6). 793-806.

Greimas, A. J. (1983 [1966]). Structural semantics: An attempt at a method. Lincoln, NE: University of Nebraska Press.

Hall, S. (1985). Signification, representation, ideology: Althusser and the poststructuralist debates. Studies in Mass Communication, 2(2), 91-114.

Halliday, M. A. K. (1985). An introduction to functional grammar. London: Edward Arnold.

Harris, T. (2002). Basket weavers and true believers: The middle class left and the ALP Leichhardt municipality, c. 1970-1990. Sydney: University of New South Wales $\mathrm{PhD}$ thesis.

Hasan, R. (1978). Text in the systemic-functional model. In W. Dressler (Ed.), Current trends in textlinguistics, (pp. 228-246). Berlin \& New York: Walter de Gruyter.

Hodge, B. (1995). Monstrous knowledge: Doing PhDs in the new humanities. Australian Universities' Review, 38(2), 35-39.

Hood, S. (2010). Appraising research: Evaluation in academic writing. Basingstoke: Palgrave Macmillan.

Hyon, S. (1996). Genre in three traditions: Implications for ESL. TESOL Quarterly, 30(4), 693-722.

Jackson, B. S. (1998). Truth or proof?: The criminal verdict. International Journal for the Semiotics of Law, 11(3), 227-273.

Jordonova, L. (2000). History in practice. London: Arnold.

Lévi-Strauss, C. (1963 [1958]). Structural anthropology (Vol. I). New York, NY: Basic Books.

Lévi-Strauss, C. (1966 [1962]). The savage mind. Chicago, IL: University of Chicago Press.

Lévi-Strauss, C. (1976 [1973]). Structural anthropology (Vol. II). New York, NY: Basic Books.

Lévi-Strauss, C. (1984 [1960]). Structure and form: reflections on a work by Vladimir Propp. In V. Propp, Theory and history of folklore, (pp. 167-188). Minneapolis, MN: University of Minnesota Press.

Lewin, B., Fine, J. and Young, L. (2001). Expository discourse: A genre based approach to social science research texts. New York: Continuum.

Lorés, R. (2004). On RA abstracts: From rhetorical structure to thematic organisation. English for Specific Purposes, 23(3), 280-302.

Martin, J. \& Rose, D. (2008). Genre relations: Mapping culture. London: Equinox.

Ondaatje, M. (2007). Neither counterfeit heroes nor colour-blind visionaries: Black conservative intellectuals in modern America. Perth: University of Western Australia PhD thesis. 
Paltridge, B. (1995). Working with genre: A pragmatic perspective. Journal of Pragmatics, 24(4), 393-406.

Paltridge, B. (1997). Genre, frames and writing in research settings. Amsterdam: John Benjamins.

Paltridge, B. (2002). Thesis and dissertation writing: An examination of published advice and actual practice. English for Specific Purposes, 21(2), 125-143.

Posner, M. (1986). Empirical studies of prototypes. In C. G. Craig (Ed.), Noun Classes and Categorization (pp. 53-61). Amsterdam: John Benjamins.

Propp, V. (1968 [1927]). Morphology of folklore. Austin, TX: University of Texas Press.

Rosch, E. (1975). Cognitive representations of semantic categories. Journal of Experimental Psychology: General, 104, 192-233.

Rosch, E. (1978). Principles of categorization. In E. Rosch and B. Lloyd (Eds.), Cognition and categorization (pp. 27-48). Hillsdale, NJ: Erlbaum.

Samraj, B. (2002). Introductions in research articles: Variations across disciplines. English for Specific Purposes, 21, 1-18.

Sawaki, T. (2014). A comparative study of traditional and postmodern academic writing corpora. English Text Construction, 7(2), 178-214.

Swales, J. (1981). Aspects of article introduction. Birmingham: University of Aston.

Swales, J. (1990). Genre analysis: English in academic research settings. Glasgow: Cambridge University Press.

Swales, J. (2004). Research genres: Explorations and applications. Cambridge, UK: Cambridge University Press.

Upton, S. (2009). The impact of migration on the people of Papua, Indonesia: A historical demographic analysis. Sydney: University of New South Wales $\mathrm{PhD}$ thesis.

Wittgenstein, L. (1958). Philosophical investigations. Oxford: Basil Blackwell.

Author address

School of the Arts and Media, University of New South Wales, Sydney, NSW 2052, Australia

info@tomokosawaki.com

About the author

Tomoko Sawaki received her $\mathrm{PhD}$ in English Linguistics from University of New South Wales. Her main research interests are English for Academic Purposes, Corpus Linguistics and Semiotics. 